Anuario Latinoamericano Ciencias Políticas

y Relaciones Internacionales

vol. 6, 2018

pp. 85-101

\section{La geopolítica argentina relegada por condicionantes domésticos (2001-2017). Una mención al caso de la Triple Frontera}

DOI: 10.17951/al.2018.6.85-101

\section{Argentina's geopolitics relegated by domestic determinants (2001-2017). A mention to the Tri-Border case}

\author{
Priscila Palacio $^{*}$ \\ FACULTAD DE CIENCIAS ECONÓMICAS \\ UNIVERSIDAD DE BUENOS AIRES, ARGENTINA \\ $\triangle$ prisilun@gmail.com \\ https://orcid.org/0000-0002-9773-4160
}

\title{
RESUMEN
}

En los primeros lustros del siglo, mientras la geopolítica resurgió a nivel mundial, el Estado argentino relegó la formulación de una geopolítica por condicionantes domésticos. Desde el 2001, las urgencias sociales pesaron en la agenda gubernamental. Con los Kirchner, se profundizó el proteccionismo y abrazó la integración sudamericana -pero no económica; se retomó el reclamo por las Malvinas, pero desguarneció las fronteras. Se explicitó el desprestigio de la geopolítica y la ausencia del Estado en la Triple Frontera. Desde 2016, Macri reformuló la política de seguridad por razones domésticas. Se reforzó el control fronterizo y acercó a EE. UU. No hubo politica geoestratégica para la Triple Frontera.

PALABRAS CLAVE: geopolítica argentina, Triple Frontera, relaciones internacionales.

\footnotetext{
ABSTRACT

At the beginning of this century, while geopolitics resurged worldwide, the Argentine state relegated the formulation of geopolitics because of domestic determinants. Since 2001, pressing social needs marked the government agenda. The Kirchners

* Profesora Adjunta de la Facultad de Ciencias Económicas, Universidad de Buenos Aires. Doctora en Relaciones Internacionales. Magíster en Relaciones Económicas Internacionales. Contador Público Nacional. Miembro del Centro de Estudios Latinoamericanos para el Desarrollo y la Integración (FCE-UBA).
} 


\begin{abstract}
Dossier América Latina: fronteras y zonas fronterizas

pursued the protectionism and embraced the integration of South America, however not in its economic dimension; they retook the Falklands' claim, but left the borders unprotected. It made explicit the discrediting of geopolitics and the absence of the State in the Tri-Border. From 2016, Macri reshaped security policy because of domestic causes. He strengthened border control and approached the United States. There was no strategic policy for the Tri-Border.
\end{abstract}

KEYWORDS: Argentina's geopolitics, Tri-Border, international relations.

\title{
Introducción
}

Desde una mirada realista de las relaciones internacionales, el trabajo sostiene que, en los primeros lustros del siglo XXI, el Estado argentino relegó la formulación de una geopolítica debido a condicionantes domésticos (sociales, económicos y políticos) ${ }^{1}$ que se registraron desde el año 2001. El estudio espera contribuir al análisis del rol de los factores domésticos en la política exterior, siguiendo el enfoque de Gilpin (1981), Snyder (1991), Koslowski y Kratochwil (1994), Kirshner (2010), entre otros autores.

A fin de contextualizar el desarrollo del tema, el trabajo principia con una referencia a la evolución de la geopolítica como disciplina -tanto en el ámbito internacional como nacional. El análisis ayuda a comprender, con mejor grado de aproximación, por qué - mientras la geopolítica resurgió a nivel mundial- la misma fue desprestigiada desde el imaginario social argentino.

Seguidamente, el estudio se focaliza en la evolución que registró Argentina desde la crisis del 2001. A partir de entonces, las urgencias domésticas se impusieron en la agenda gubernamental, dejando de lado la formulación de una geopolítica nacional. Bajo las gestiones de Néstor y Cristina Kirchner, el país profundizó el proteccionismo, a la vez que abrazó la retórica de revitalización de la integración latinoamericana. No obstante, se avanzó más en el consenso político que en la cooperación económica. Ello explica el languidecimiento del MERCOSUR y el relativo enfriamiento de las relaciones regionales, cuando cambiaron los signos políticos de algunos gobiernos latinoamericanos (incluida la Argentina).

Por otra parte, debido al tinte ideológico que sostuvieron los gobiernos Kirchner, se observó el predominio de un idealismo de forma en la estrategia exterior argentina. Si bien se retomó el reclamo por la soberanía en Malvinas, se evidenció una menor presencia del Estado argentino en zonas fronterizas - movilizando la gendarmería hacia tareas de seguridad interna. La Triple Frontera fue un reflejo de esa geopolítica postergada (o desprestigiada) en la agenda gubernamental.

1 Se entiende por condicionantes domésticos: la estructura económica nacional, las ideologías políticas, los grupos de poder, la estructura social, entre otros factores propios de cada Estado. 
En 2016, debido al incremento de la inseguridad interna, el gobierno de Mauricio Macri empezó a revisar la política de seguridad. Se reforzó el control fronterizo y el país volvió a estrechar lazos con Estados Unidos, alejándose de la agenda regional antes impulsada por los Kirchner. Hacia 2017, continuó observándose la parálisis del MERCOSUR y tampoco se evidenció la formulación de una política para repensar la importancia geoestratégica de la Triple Frontera (más allá del tema del narcotráfico).

\section{La geopolítica: del desprestigio al resurgimiento en el ámbito mundial}

En los albores del nuevo milenio, la geopolítica irrumpió de nuevo en la palestra mundial, tanto en los estudios internacionales como en la política exterior de los grandes Estados. Evans y Newnham (1998) definen a la geopolítica como un método de análisis de la política exterior que busca comprender, explicar y predecir el comportamiento político internacional, especialmente en términos de variables geográficas (localización, tamaño, clima, topografía, demografía, recursos, desarrollo tecnológico, etc.). Para Barrios (2009: 193), se trata de un área de análisis multidisciplinario de las ciencias sociales que estudia la influencia de los factores geográficos en la vida y evolución de los Estados, a fin de extraer conclusiones que sirvan al estadista en la conducción de la política interna y externa del Estado. Como sostiene Fornillo:

...[La] geopolítica [...] bien parecería una sub-disciplina sin fronteras claras. [...] A veces se recuesta en la ciencia política y opera como una 'conciencia geográfica del Estado', a veces linda con las relaciones internacionales $y$ le transfiere su sabida agresividad.

(Fornillo 2015: 120)

Pese a su irrefutable relevancia para las relaciones internacionales, Evans y Newnham señalan que, en la segunda mitad del siglo XX, la geopolítica perdió prestigio en la academia occidental por su asociación con la política alemana del Tercer Reich (lebensraum) ${ }^{2}$. No obstante, aunque reconocen que sigue existiendo la tendencia a esa connotación en la disciplina, consideran que tuvo un efecto desafortunado en el estudio de la geopolítica, sobre todo en Estados Unidos y Reino Unido.

2 Si bien la geopolítica alemana había nacido con los trabajos de Rudolf Kjellén [18641922] y Friedrich Ratzel [1844-1904], su estudio cobró impulso bajo el Instituto de Geopolítica de Munich, fundado en 1924 por Karl Haushofer, asesor y académico influyente del gobierno de Hitler (Evans y Newnham 1998: 198).
La geopolítica argentina relegada por condicionantes domésticos (2001-2017). Una mención al caso de la Triple Frontera

Priscila Palacio 
Dossier América Latina: fronteras y zonas fronterizas
Muchos concluyeron que el estudio de la geografía en conjunción con la política significaba una obsesión con la estrategia, lo que a su vez representaba una predilección por la guerra y la conquista. [traducción de la autora]

(Evans, Newnham 1998: 198)

La connotación militarista y ofensiva que adquirió la geopolítica en los estudios internacionales de la segunda posguerra y la Guerra Fría no permaneció ajena a los desarrollos en el ámbito latinoamericano. En algunos países de la región, más que el "efecto maligno y siniestro" de la política de Hitler (parafraseando a Evans y Newnham), pareció evidenciarse en ciertos sectores sociales una tendencia a asociar peyorativamente la geopolítica con la "doctrina de seguridad nacional" que impulsaron los gobiernos militares durante la segunda mitad del siglo XX.

Tal parecería ser el caso de Argentina, donde, si bien los estudios sobre geopolítica aparecieron tempranamente, se registró poca producción bibliográfica en la materia. Inclusive, varios estudios sobre geopolítica fueron introducidos y/o corresponden a autores del ámbito castrense, por ejemplo, el clásico libro Introducción a la geopolítica argentina (las influencias geopolíticas en la formación de nuestro Estado) de Emilio R. Isola y Ángel C. Berra (1950), publicado por el Círculo Militar, con varias ediciones. Otra publicación es Desarrollo y seguridad de la Argentina en el marco geopolítico Internacional del Cnel. José Marini y Reinaldo Bandini (1980) -ambos profesores de la Escuela de Defensa Nacional (Argentina). También puede mencionarse Geopolítica y Subversión de José Teófilo Goyret (1980) -general e historiador militar.

Aunque podrían referirse otros autores fuera del ámbito castrense, el propósito no es efectuar un recorrido bibliográfico de la materia, sino destacar que la geopolítica -como disciplina- tuvo poco desarrollo en el país y parte de este provino del sector militar [como en la versión clásica de la disciplina] (Fornillo 2015). En cierto modo, ello podría explicar la poca relevancia que se dio a la geopolítica en Argentina, para finales del siglo XX y comienzos del XXI, tanto en el plano académico como gubernamental. Durante la restauración democrática y, sobre todo, en los años 90 , el interés nacional se volcó hacia la integración regional y la globalización económica, de manera concomitante al posicionamiento que adoptó el país en los gobiernos de Carlos Menem (1989-99).

Nuevamente, esa realidad no fue ajena a los estudios internacionales. Evans y Newnham (1998) observan hacia finales del siglo XX que -a nivel internacional y, sobre todo, en EE. UU.- todavía existía cierta negación al campo de estudio de la geopolítica, aunque empezaban a avizorar un resurgir del interés por la materia (en estudios militares). De ese modo, reconocían que, en los años 90, se registró un desplazamiento en los estudios de política exterior, pasando de la preocupación realista por la dinámica territorial y militar al énfasis neoliberal en la interdependencia y el ordenamiento de la política mundial. Así, señalaban que: 
[...] la 'geoeconomía' (o incluso 'geoinformación') se dice que ha reemplazado a la geopolítica como el motivo fundamental en la formulación y conducta de la política exterior. Sin embargo, la retención del prefijo 'geo' continúa destacando la importancia de la ubicación geográfica en las relaciones internacionales. [traducción de la autora]

(Evans, Newnham 1998: 199)
La geopolítica argentina relegada por condicionantes domésticos (2001-2017). Una mención al caso de la Triple Frontera

Priscila Palacio

No es difícil comprender ese desplazamiento en los estudios internacionales $^{3}$, cuando se consideran los grandes cambios que conllevó el abrupto fin del orden bipolar. Como señala Hutschenreuter,

.... La] geopolítica no solamente se enfrentó al fenómeno de su desnaturalización, sino a su misma desconsideración: en tanto el signo más concluyente de la globalización se manifestaba en el debilitamiento del factor territorial del mundo de los Estados [...] la propiedad de la geopolítica a partir de la cual políticamente los sujetos tradicionales de la disciplina (los Estados) encaraban ideas y prácticas, se tornaba casi irrelevante.

(Hutschenreuter 2008: 3)

En los albores de los años 90, con el vertiginoso avance de la globalización, parecieron desaparecer los conflictos geopolíticos asociados a la Guerra Fría. EE. UU. había triunfado en la contienda ideológica, económica y política mundial, consolidando el marco para el predominio de las instituciones ícono del liderazgo económico estadounidense: Fondo Monetario Internacional (FMI) y Banco Mundial (BM). De la mano de esos organismos avanzó el neoliberalismo, adquiriendo rápida difusión en la primera mitad de la década, con la incorporación en masa de economías exsoviéticas. El propio FMI reconoció que el final de la Guerra Fría tuvo grandes efectos en el organismo:

Los intereses políticos que influyen en las decisiones de préstamo del FMI ya no giraban alrededor del conflictivo eje oriente-occidente, sino de cuestiones de seguridad regional o interna o de alianzas económicas.

(Boughton 2004: 11)

La difusión del neoliberalismo fue facilitada por las innovaciones de la Tercera Revolución Industrial. Como sostuvo Frieden (2006: 378) "Aquellos que lucharon por la integración de los mercados a nivel nacional y global, habían triunfado".

[...] Tres factores eran claves en la nueva revolución financiera: la desregulación en los mercados bursátiles, bancarios y monetarios nacionales,

3 A modo de muestra del creciente interés en los estudios económicos, se destaca que en los años 1970 nació la Economía Política Internacional como disciplina autónoma. 
Dossier América Latina: fronteras y zonas fronterizas el aumento en las transacciones internacionales de capitales y la innovación en una multitud de instrumentos de inversión, seguros y especulación.

(Marichal 2010: 226-9)

A la par de esos cambios, se evidenció la propagación del estilo de vida estadounidense, como ícono de la nueva era. Alan Greenspan expresó que: “[...] la tecnología de la información estadounidense arrasó en el mercado global, como lo hicieron innovaciones que iban desde los lattes de la cafetería Starbucks a los derivados de crédito" (Greenspan 2008: 208). Todo parecía indicar que la globalización estaba cristalizándose como el paradigma imperante a nivel mundial y la economía había subsumido a los intereses geopolíticos. En los "felices años noventa" - parafraseando a Stiglitz (2003) - proliferaron términos como "globalismo", "sociedad global", "aldea global", que fueron acaparando las producciones del ámbito académico. En cierto modo, reflejaban la percepción de un cambio de época.

Sin embargo, desde mediados de la década de los 90 comenzaron a emerger los efectos negativos de la globalización: las crisis financieras. Aun así, continuaron pronunciándose adeptos a dicho modelo, entre otros, Thomas L. Friedman, quien en 1996 formuló una tesis que, años después, incluyó en The Lexus and the Olive Tree. Understanding Globalization (Friedman 1999). Para Friedman, "dos países que tuvieran respectivamente McDonald's nunca habrían hecho la guerra el uno contra el otro" (Friedman 1996, traducción de la autora $)^{4}$. Detrás de su observación -decía- podía haber “ ... [una] Teoría de los Arcos Dorados de Prevención de Conflictos, que estipula que ... [a] la gente en los países McDonald's no le gusta pelear guerras; a ellos les gusta esperar en línea por hamburguesas" (Friedman 1996, traducción de la autora).

Se trataba, sin lugar a duda, de una interpretación controversial de la globalización. Asimismo, casi paralelamente al auge de este fenómeno, empezó a desarrollarse el debate sobre la gobernanza global. Karns \& Mingst (2010) afirman que, si bien este último concepto tenía raíces antiguas, la pos-Guerra Fría, el liberalismo y la globalización influyeron en las concepciones contemporáneas del mismo. Aun así, afirman que gobernanza global no es el equivalente a gobierno global: a nivel global no hay estructura jerárquica de autoridad, como en los Estados-nación.

En la cúspide del debate sobre globalización y gobernanza global, algunos analistas advirtieron que los cambios globales tornaban anacrónica la antiquísima estructura del Estado-nación westfaliano. De haberse confirmado el anacronismo, la geopolítica no tendría razón de ser. Sin embargo, no ocurrió así.

Un número de comentaristas sobre globalización ha especulado recientemente que la lógica del desarrollo económico moderno está haciendo al esta-

${ }^{4}$ El autor planteaba como excepciones a su formulación la Guerra de Malvinas (1982) y las guerras civiles. 
do innecesario. [...] muchos de los consultores de gestión exitosos de los años 1990 han sugerido que, con el avance contemporáneo de la globalización, el estado tiene los días contados. [traducción de la autora]

(Scholte 1997: 427)

Kenichi Ohmae, en The End of the Nation State. The Rise of Regional Economies (1995), planteó la posible configuración de un mundo sin fronteras, donde la economía pasaría a regir las actividades sociales a nivel global. Para Ohmae, esa configuración ya estaba sucediendo con la transnacionalización y el vertiginoso avance de las tecnologías de información y comunicación.

Debemos, tanto los directivos empresariales como los politicos, hacer frente a la incómoda y difícil realidad: la vieja cartografía ya no sirve.

(Ohmae 1997: 26-7, 37)

Una interpretación similar, aunque más moderada, provino de Susan Strange que, en The Retreat of the State. The Diffusion of Power in the World Economy (1996), destacaba -si bien no la desaparición de los Estados- el avasallador avance de la economía de mercado sobre la capacidad de acción de los mismos.

...[El Estado] está atravesando una metamorfosis causada por el cambio estructural en la sociedad y en la economía mundiales.

(Strange 2003: 105, 112)

En ese contexto, se explica que varios analistas señalaran el triunfo de la geoeconomía sobre la geopolítica. Pero, como señala Scholte (1997: 427-8), también surgieron refutaciones de autores que se resistían al fin del Estado; entre ellos, Paul Hirst y Grahame Thompson, quienes afirmaron que los argumentos sobre globalización eran exagerados, porque los Estados retenían capacidades cruciales de gobierno.

Más allá del debate académico, los acontecimientos se impusieron de manera drástica a inicios del siglo XXI. Los atentados del 11 de septiembre de 2001 marcaron un nuevo punto de inflexión en la historia mundial. La geopolítica resurgió de manera abrupta, no sólo en los estudios sobre terrorismo y seguridad internacional, sino también, en la agenda gubernamental de los grandes Estados. La globalización empezó a ser cada vez más cuestionada -incluso, en el corazón de la economía mundial (EE.UU.).

Al parecer, los más reticentes tenían razón: pese al vertiginoso avance de la globalización en los años 90, su alcance fue parcial y limitado. Frente a ella, los Estados retuvieron su tradicional cuota de poder -que sacarían a la luz cuando las crisis económicas y/o de seguridad domésticas lo requieran.
La geopolítica argentina relegada por condicionantes domésticos (2001-2017). Una mención al caso de la Triple Frontera

Priscila Palacio 


\section{Dossier \\ América Latina: \\ fronteras y zonas \\ fronterizas \\ La geopolítica del Estado argentino, relegada por condicionantes domésticos (2001-2017)}

Al abordar la geopolítica del Estado argentino en los primeros lustros de este siglo, es imprescindible referirse a las circunstancias domésticas que afrontó el país en dicho período. Las mismas fueron determinando las prioridades de la agenda gubernamental -más allá de la incidencia de la coyuntura internacional y regional ${ }^{5}$.

La crisis del 2001 marcó un hito en la historia argentina reciente. Hacia finales de ese año, el desempleo alcanzó la alarmante cifra del $18 \%$; las reservas del Banco Central eran exiguas para responder al régimen de conversión (vigente desde $1991^{6}$ ) y al elevado endeudamiento externo. La economía se hallaba sumida en una depresión y, diversos sectores sociales estaban movilizados. En el arco opositor al gobierno de Fernando de la Rúa (1999-2001) y en el imaginario social entraron en cuestión los paradigmas que el país abrazó durante los años 90. Cundió la crítica al neoliberalismo y la globalización considerados responsables de los males que azotaban a la sociedad argentina. En los últimos días de su gestión, la emergencia obligó al país a iniciar un desacople de la economía mundial. El corralito ${ }^{7}$ restringió el libre flujo de capitales que, junto a la convertibilidad, habían dejado a la Argentina a las puertas del default ${ }^{8}$.

La renuncia del presidente De la Rúa -tras las protestas e incidentes del 19 y 20 de diciembre de 2001, condujo a la "acefalía". Por primera vez, el país tendría cinco presidentes en el curso de dos meses (Palacio 2012: 127). Sin embargo, la situación se estabilizó con la asunción de Eduardo Duhalde (2002-2003), como presidente provisorio. En su gestión, la economía se encaminó en el sendero del proteccionismo, buscando alcanzar un piso de estabilidad social. El gobierno abandonó la convertibilidad y devaluó el peso para equilibrar la balanza comercial. La caída de importaciones impulsó el gradual resurgimiento de la actividad industrial y la paulatina recuperación del empleo y la demanda doméstica. La devaluación posibilitó instaurar retenciones - para aumentar la recaudación fiscal.

La economía argentina inició un repunte a partir del 2003, facilitado por un excepcional período de alza en los precios de los commodities. El boom

5 Sobre el impacto de éstas últimas en la política exterior argentina, pueden hallarse varios análisis, entre otros, el que plantea Miranda (2012).

6 Ley de convertibilidad $\mathrm{N}^{\circ} 23.928 / 91$ establecía una paridad cambiaria fija de 1 peso $=$ 1 dólar estadounidense. Fue derogada a inicios del año 2002 por el presidente Eduardo Duhalde.

7 Dto. 1570/2001, implementado durante la breve gestión del Mtro. de Hacienda, Domingo Cavallo.

8 Declarado el 31/12/2001, en la efímera gestión del presidente Rodríguez Saá (Palacio 2012: 127).

9 Debido a que su vicepresidente, Carlos “Chacho” Álvarez, había renunciado el 6 de octubre del 2000. 
de la soja y otras materias primas apuntaló el crecimiento doméstico, permitiendo la estabilización política durante la siguiente gestión del presidente Néstor Kirchner (2003-2007). Bajo su gobierno, se produjeron algunas transformaciones. El país pasó de una política de "relaciones carnales con Estados Unidos" 10 -durante los noventa, a propiciar el fracaso de la propuesta estadounidense de integración económica de América: el ALCA. La nueva geopolítica quedó en evidencia cuando -en paralelo a la IV Cumbre de las Américas (noviembre de 2005), en la que George Bush pretendió impulsar el ALCAArgentina permitió la realización de una "contracumbre", la III Cumbre de los Pueblos, protagonizada por Hugo Chávez, cuyo lema era "no al ALCA" (La Nación 29/10/2005).

Al tiempo que la estrategia exterior argentina le dio la espalda a EE. UU., abrazó la revitalización de la integración con los países sudamericanos. Duhalde, titular de la Comisión de Representantes del MERCOSUR durante la gestión de Néstor Kirchner, fue uno de los asistentes a la creación de la Comunidad Sudamericana de Naciones (CSN), para finales del año 2004. Dicha entidad se propuso integrar a los países del Sur con infraestructura básica, desarrollo y explotación de los recursos naturales, energéticos y de comunicaciones (La Nación, 08/12/2004). En 2008, la CSN fue reformulada y pasó a ser Unión Sudamericana de Naciones (UNASUR) -foro que tuvo un activo rol en algunas crisis de la región.

Asimismo, Néstor Kirchner decidió profundizar la integración sociopolítica con América Latina (política que continuaría luego su esposa, Cristina Fernández de Kirchner). En 2004, se lanzó el Programa Nacional de Normalización Documentaria Migratoria, "Patria Grande", creado en el ámbito de la Dirección Nacional de Migraciones, por el Decreto No 836/2004. Su objetivo fue regularizar la inserción e integración de los extranjeros residentes de manera irregular en el país. Por el Decreto № 578/2005, se instruyó a la Dirección Nacional de Migraciones a implementar la regularización migratoria de los extranjeros nativos de los Estados Parte del Mercosur y sus Estados Asociados (Ministerio del Interior de la República Argentina). La legislación facilitó la movilidad transfronteriza y la radicación de inmigrantes en Argentina. El país se constituyó en un polo de atracción para inmigrantes de otros países, seducidos por la nueva normativa migratoria y el crecimiento que evidenciaba la economía argentina desde 2003. Como señala el informe de SELA (2014: 21), “[En MERCOSUR] El país con más inmigrantes es Argentina".

No obstante, ese crecimiento del PBI argentino en los primeros lustros del dos mil no fue acompañado por un mismo ritmo de crecimiento del empleo formal y muchos inmigrantes fueron a engrosar el sector informal de la economía. A pesar de que el INDEC mostraba una caída significativa del des-

10 Como eufemísticamente lo denominó Guido Di Tella, Canciller del presidente Menem (1989-1999).
La geopolítica argentina relegada por condicionantes domésticos (2001-2017). Una mención al caso de la Triple Frontera

Priscila Palacio 
Dossier América Latina: fronteras y zonas fronterizas empleo (en el segundo lustro del dos mil), la exteriorización de la economía informal fue creciendo -al punto que la mayor feria de economía informal en Argentina, "La Salada", llegó a desplazar en importancia a la tradicional feria de Ciudad del Este en Paraguay (Palacio, Papi, Purciariello 2016: 57).

En cuanto a la integración económica regional, no corrió con la misma suerte. Las dificultades que, desde inicios del dos mil, arrastraban las grandes economías de Argentina y Brasil, los llevó a privilegiar sus mercados domésticos en detrimento del comercio intrazona. Se paralizó virtualmente el MERCOSUR, ya que uno de los pilares del Tratado de Asunción (1991) fue crear una zona de libre comercio (ZLC) -para avanzar luego en la unión aduanera y el mercado común. Como señala el informe de la SELA:

A inicios de este siglo, crecieron las barreras técnicas al comercio, los impuestos domésticos aplicados de forma discriminatoria, la proliferación de medidas antidumping en el comercio intrarregional, y las restricciones cuantitativas de facto a través del mecanismo de las licencias no automáticas. Luego de las crisis muchos de los instrumentos aplicados no fueron removidos, sino que se mantuvieron y volvieron a usarse intensamente en el período reciente (2008-2013). (SELA 2014: 13)

El arancel externo común (AEC), que se negoció en el Tratado de Ouro Preto (1994) y debía poner en marcha la unión aduanera (UA), tampoco logró implementarse. El informe de SELA sostiene que:

[...] 20 años después de iniciado el proceso de construcción de la unión aduanera muy poco se avanzó. Hay un conjunto de decisiones [...] que buscaron construir un programa de trabajo consistente en particular a partir del año 2004 (Decisión 54/04). Sin embargo, desde el año 2008 se vienen incumpliendo los plazos [...]. El resultado son muchas normas y pocos o nulos compromisos efectivos. (SELA 2014: 16)

En la actualidad, ni la ZLC ni la UA están funcionando plenamente en MERCOSUR. Sumada a ello, la propuesta de incorporación de Venezuela (en 2005) al bloque, generó disidencias internas, dilatando su aprobación hasta el año 2012. A raíz del rezago del MERCOSUR, algunos países explicitaron su decisión por avanzar en alianzas económicas con países extrazona, sobre todo con EE. UU. y China, amenazando con romper el Acuerdo.

De ese modo, en el marco de una retórica nacionalista y latinoamericana con prédica industrialista y estatista, las presidencias de Néstor Kirchner y Cristina Fernández de Kirchner (2007-15) alzaron la bandera de reivindicación de los derechos humanos en referencia a los crímenes cometidos por el gobierno de facto (1976-83). El discurso oficial mantuvo un fuerte cuestionamiento al accionar de las fuerzas armadas y al monopolio de la fuerza por parte del Estado. Desde la icónica imagen de Néstor Kirchner ordenando 
descolgar los retratos de los presidentes de facto ${ }^{11}$, hasta la reducción presupuestaria que recayó sobre las fuerzas armadas, ambos gobiernos explicitaron su constante malestar con ese sector de la burocracia estatal.

Aun así, resultó paradójico que la gendarmería (fuerza encargada del control fronterizo) adquiriera un nuevo rol durante el gobierno de Cristina Kirchner, abocándose a tareas de seguridad interna. Para finales del 2010, la presidente lanzó el Operativo Centinela, con el fin de destinar efectivos de gendarmería para el control del territorio bonaerense por la creciente inseguridad en la Provincia de Buenos Aires. Indudablemente, el desplazamiento de la gendarmería fue en detrimento del control de las zonas fronterizas del país. La Triple Frontera no escapó a esa realidad nacional.

\section{La Triple Frontera: un reflejo de la geopolítica postergada en la agenda gubernamental}

Desde los años noventa, la Triple Frontera fue señalada como el lugar desde donde provinieron los autores de los atentados a la Embajada de Israel (1992) y a la Asociación Mutual Israelita Argentina - AMIA (1994). En 1998, Argentina y los países lindantes firmaron el Plan de Seguridad para la Triple Frontera, con el fin de crear comisiones y acciones específicas para la región (Milia 2015: 118). Más allá de este acuerdo, no se observó que la Triple Frontera figurara entre las prioridades de la política gubernamental argentina ni en los 90 ni en los primeros lustros del dos mil.

Según surge de un cable diplomático de Paraguay (del 29/12/2008), difundido por WikiLeaks, los gobiernos de la Triple Frontera (Argentina, Brasil y Paraguay) han estado preocupados desde hace tiempo por la existencia de contrabando de armas y drogas, lavado de dinero, producción y comercialización de mercancías ilegales, entre otras actividades ilícitas que tendrían lugar en la región. En 2002, a propuesta de estos países, EE. UU. se unió con ellos en el "Grupo 3+1 sobre Seguridad en el Área de la Triple Frontera”, con el propósito de mejorar las capacidades de los tres países para detectar el crimen transfronterizo y evitar el lavado de dinero y financiamiento de potenciales terroristas. EE. UU. ha demostrado su preocupación de que simpatizantes de Hezbollah y Hamás estuvieran incrementando sus fondos en la región. No obstante, el cable revela que tal información no había sido corroborada (hasta ese momento), así como tampoco la presencia de extremistas islámicos en el lado paraguayo de la Triple Frontera (WikiLeaks, 2008). Pese a ello, la región siguió en la mira internacional.

Desde una perspectiva realista de las relaciones internacionales, los gobiernos de Néstor y Cristina Kirchner explicitaron un "idealismo" de forma en

11 Los retratos de Jorge R. Videla (1976-1981) y Reynaldo Bignone (1982-1983) fueron quitados de la "Galería de Directores" del Colegio Militar, el 24 de marzo de 2004 (Télam $17 / 05 / 2013)$.
La geopolítica argentina relegada por condicionantes domésticos (2001-2017). Una mención al caso de la Triple Frontera

Priscila Palacio 
Dossier América Latina: fronteras y zonas fronterizas

la política exterior argentina. Si bien reivindicaron el reclamo por la soberanía en las Islas Malvinas (aunque sin lograr avances en ese plano) e impulsaron la profundización de la integración (política) de América Latina, se descuidó la presencia del Estado argentino en zonas fronterizas. Además, ambos presidentes evidenciaron poco interés por concertar acuerdos en temas relativos a la Triple Frontera con los países lindantes (Brasil y Paraguay). Ello implicó que Argentina fuese quedando al margen de las negociaciones bilaterales que enhebraron los dos vecinos.

En 2009, Brasil y Paraguay iniciaron negociaciones para un acuerdo bilateral con miras a la gradual formalización del flujo comercial transfronterizo (entre Foz de Iguazú y Ciudad del Este), que empezó a regir en 2012 ${ }^{12}$. Argentina no fue parte de esas negociaciones y se limitó a establecer un "tope de compras exentas" para los residentes nacionales que ingresen productos desde el exterior. El “tope" es fácilmente burlado, ya que se controla de manera aleatoria por la policía aduanera de Puerto Iguazú ${ }^{13}$. Aunque la formalización del comercio transfronterizo brasileño-paraguayo avanzó de modo gradual (Primera Plana 17/12/2014), las transacciones registradas crecieron de manera significativa (Primera Plana 17/02/2016).

Por otra parte, la cooperación entre Brasil y Paraguay se extendió a otras áreas, como la asistencia técnica que Brasil proveyó a la Secretaría de Prevención de Lavado de Dinero (SEPRELAD) de Paraguay (WikiLeaks 2008). En 2017, tuvo lugar un histórico acercamiento militar entre ambos países, concertando ejercicios conjuntos (Operación Paraná) para formar a cuadros oficiales de los ejércitos (Sputnik Mundo 22.07.2017).

Según el portavoz de la fuerza terrestre paraguaya, este 'ejercicio escuela' es la concreción de varias 'reuniones bilaterales'. Torres [Jefe de Comunicación del Ejército de Paraguay] indicó que es 'un medio de fortalecer la cooperación entre ambos ejércitos, no sólo en los papeles sino en el terreno con operaciones tácticas. [...] El lugar donde se lleva a cabo es cercano a la Triple Frontera [...].

(Sputnik Mundo 22.07.2017)

Tampoco se registró la injerencia argentina en dichos acuerdos. Por el contrario, el mencionado desplazamiento de efectivos de gendarmería hacia tareas de seguridad interna desguarneció la presencia argentina en la Triple Frontera. A consecuencia de ello y debido al incremento de la problemática del narcotráfico (donde la Triple Frontera fue señalada como una de sus

12 Conocido como "RTU" (Régimen de Tributación Unificado) en Brasil y, "RFC" (Régimen Fronterizo de Comercialización) en Paraguay, el acuerdo se propuso formalizar el flujo comercial que realizan los "sacoleiros" (microempresarios brasileños) en Ciudad del Este (Palacio 2016: 423-4). Iguazú.

13 Según lo observado in situ por el autor, en diversas visitas efectuadas a la región de Puerto 
puertas de ingreso al país), a mediados del 2011 el gobierno de Cristina F. de Kirchner tuvo que implementar el Operativo Escudo Norte.

... [El] Operativo Escudo Norte, un plan de vigilancia del territorio y de lucha contra las incursiones ilegales en el país para atacar el tráfico de drogas en las fronteras. Este programa refuerza la seguridad en el norte de la Argentina y se complementa con el Operativo Centinela en el conurbano bonaerense y el Plan Unidad Cinturón Sur, que funciona en la ciudad de Buenos Aires.

Para combatir el delito y la violencia asociados al narcotráfico en el norte del país, el Gobierno nacional diseñó una estrategia inteligente que echa mano de todos los recursos de los que dispone el Estado, desde agentes suplementarios de Gendarmería y Prefectura hasta modernos radares militares, helicópteros, aviones y embarcaciones de los sistemas de Seguridad y Defensa que serán puestos al servicio de la lucha contra el crimen organizado.

(Ministerio de Seguridad de la Nación 25.07.2011)

Varios analistas cuestionaron los resultados obtenidos en dicho operativo, debido a la insuficiencia presupuestaria y tecnológica de Argentina para llevar adelante un efectivo control fronterizo, sobre todo, en el espacio aéreo (Trombetta 2017).

En los primeros meses del gobierno de Mauricio Macri (iniciado en diciembre de 2015), la política de seguridad interna y fronteriza empezó a ser revisada -por la creciente inseguridad doméstica. El Decreto $N^{\circ} 228 / 2016$, declaró la Emergencia de Seguridad Pública (prorrogada hasta fines de 2017, por el Decreto $\mathrm{N}^{\circ}$ 50/2017). El Operativo Escudo Norte se reformuló con el Operativo Fronteras, que se creó con carácter permanente. El decreto introdujo, entre otras reformas, la posibilidad del derribo de aviones sospechosos luego de cumplir con una serie de procedimientos de advertencias (según la reglamentación). Por otra parte, se creó el Gabinete de Seguridad Humana, a fin de lograr la ejecución de las políticas de Estado en materia de seguridad y lucha contra el delito, crimen organizado, corrupción, trata de personas y narcotráfico.

En junio de 2017, por la Resolución N 565-E/2017 del Ministerio de Seguridad, se creó la organización Operativos Conjuntos Abiertos de Fronteras (OCAF), para la gestión de la coordinación interfuerzas e interagencial en la Zona de Seguridad de Fronteras (creada por Dto. N 27/2017). Los OCAF tendrán carácter permanente y una sede designada. Se estableció que el Secretario de Fronteras actuará como coordinador general de las Fuerzas de Seguridad y Fuerzas Policiales que participen de los OCAF - que serán: Gendarmería Nacional Argentina, Prefectura Naval Argentina, Policía de Seguridad Aeroportuaria y Policía Federal Argentina (pudiendo incorporarse las policías provinciales). Ya en febrero de 2016, el Ministerio de Seguridad había informado que:
La geopolítica argentina relegada por condicionantes domésticos (2001-2017). Una mención al caso de la Triple Frontera

Priscila Palacio 
Dossier América Latina: fronteras y zonas fronterizas
[...] Gendarmería irá recuperando, paulatinamente y de manera planificada, su rol de control de la frontera, para frenar el avance del narcotráfico, que es uno de los ejes centrales de nuestra política en seguridad.

(Ministerio de Seguridad 15.02.2016)

Aunque el gobierno de Macri ha evidenciado esfuerzos por reformular la política de seguridad y control fronterizo, nuevamente, por razones de seguridad interna, su gestión no explicitó hasta el momento la formulación de una política destinada a repensar la significancia de la Triple Frontera desde el punto de vista geoestratégico, geoeconómico y geopolítico, para la Argentina. Asimismo, tampoco mostró la decisión de reactivar el MERCOSUR -que sigue languideciendo no sólo por las trabas al comercio intrazona, sino por el cambio de signo político que experimentaron países de la región.

En los meses que transcurrieron de su gestión, Macri se abocó a reformular la política exterior argentina, volviendo a estrechar lazos con EE. UU. -en momentos en que dicho país se vuelca al proteccionismo económico, y distanciándose de los gobiernos de ideología izquierda que persisten en América Latina.

\section{Conclusiones}

En los primeros tres lustros de este siglo, mientras la geopolítica resurgió a nivel mundial, el Estado argentino relegó la formulación de una geopolítica nacional debido a diversos condicionantes domésticos (sociales, económicos y políticos). En primer lugar, la crisis del 2001 llevó a que las urgencias sociales determinaran las prioridades de la agenda gubernamental y Argentina se encaminó en la senda del proteccionismo. Pero una vez superadas las urgencias y retomado el crecimiento, la ideología de los gobiernos Kirchner profundizó el cierre de la economía, a la vez que abrazó un retórico acercamiento con sus pares latinoamericanos, lo cual no se tradujo en la revitalización de la integración económica regional. Ello conllevó al estancamiento del MERCOSUR y al enfriamiento de las relaciones sudamericanas, una vez que ocurrieron los cambios de signos políticos en algunos países de la región.

Asimismo, se observó que todavía persisten en ciertos sectores de la sociedad argentina las secuelas que dejaron los estragos del último gobierno militar que llevan a asociar peyorativamente la geopolítica con el accionar de las fuerzas militares. Ello explica, en algún modo, el desprestigio de la geopolítica durante los gobiernos Kirchner, aun cuando insistieran en el reclamo por Malvinas.

Claro está que la geopolítica abarca mucho más que la seguridad fronteriza. Implica una visión estratégica del posicionamiento geográfico, económico y político del país en el ámbito regional e internacional. La Triple Frontera -como Malvinas- es una región geoestratégica para Argentina; no sólo por su localización, sino por su riqueza potencial para el futuro desenvolvimiento del país. Sin embargo, ello no se reflejó en las agendas de gobierno ni cuando hubo una 
coyuntura internacional favorable para Argentina y los gobiernos latinoamericanos eran afines a la ideología de los Kirchner ni cuando empezó a cambiar la coyuntura mundial (a partir del 2008) y las ideologías de izquierda comenzaron a retroceder en la región. Pero tampoco se formuló una política geoestratégica para la Triple Frontera en los casi dos años transcurridos del gobierno de Macri (más allá de reforzar la seguridad por la problemática del narcotráfico).

Como si se tratara de un condicionamiento histórico, Argentina ostenta un territorio cuya extensión geográfica supera el alcance del control estatal y la visión geoestratégica de los respectivos gobiernos. En parte, ello responde a la relativa incapacidad económica y tecnológica para resguardar y promover el desarrollo de su vasto territorio. Además, lamentablemente, ha estimulado las apetencias de países foráneos (como Gran Bretaña), para continuar reclamando partes alejadas del control central (Malvinas). La definición de una geopolítica nacional continúa siendo, al momento, una materia pendiente de los gobiernos argentinos.

Por otra parte, el declarado interés de EE. UU. por mantener presencia en la Triple Frontera ha levantado diversas especulaciones por parte de conspicuos analistas; principalmente, debido al caudal hídrico que contiene el Acuífero Guaraní.

Finalmente, más allá de las circunstancias internacionales y regionales, la historia argentina sigue demostrando que, sistemáticamente, la coyuntura se impone a la estrategia. Además, y aunque Argentina no es parte de los grandes Estados, que los factores domésticos (económicos, sociales y políticos) sopesan en la definición de la política exterior. Ello permite explicar los cambios cruciales de política exterior que realizaron los gobiernos que se sucedieron entre fines del siglo XX e inicios del XXI: Menem, Kirchner y Macri.

\section{Referencias bibliográficas}

Barrios M. (dir.) (2009), Diccionario latinoamericano de seguridad y geopolítica, $1^{\circ}$ ed., Ed. Biblos, Buenos Aires, Argentina.

Boughton J. M. (2004), El FMI a los 60. Reflexiones sobre la reforma del FMI y las exigencias de una economía mundial en evolución, Finanzas y Desarrollo, Fondo Monetario Internacional (FMI), septiembre de 2004, https://www.imf.org/external/pubs/ft/fandd/spa/2004/09/pdf/ boughton.pdf [Consultado el 10.12.2014].

Evans G., Newnham J. (1998), Dictionary of International Relations, Penguin Books, London, England.

Fornillo B. (2015), Centralidad y permanencia del pensamiento geopolítico en la historia reciente de Sudamérica (1944-2015), "Estudios Sociales del Estado", vol. 1, no 2, segundo semestre de 2015, http://www.estudiossocialesdelestado.org/index.php/ese/article/view/46 [Consultado el 03.10.2016]

Frieden J. A. (2006), Global Capitalism. Its Fall and Rise in the Twentieth Century, Norton and Company, USA.
La geopolítica argentina relegada por condicionantes domésticos (2001-2017). Una mención al caso de la Triple Frontera

Priscila Palacio 
Dossier América Latina: fronteras y zonas fronterizas
Friedman T. L. (1996), Foreign Affairs Big Mac I, The Opinion Pages, "The New York Times", 8 de diciembre de 1996, http://www.nytimes.com/1996/12/08/opinion/foreign-affairs-bigmac-i.html [Consultado el 20.09.2014]

Gilpin R. (1981), War and Change in World Politics, Cambridge University Press, United Kingdom [Reimpresión 1999].

Goyret J. T. (1980), Geopolítica y subversión, Ed. Depalma, Buenos Aires, Argentina.

Greenspan A. (2008), La era de las turbulencias. Aventuras en un nuevo mundo, Título original: The Age of Turbulence, trad. Gabriel Dolls Gallardo, Ediciones B.S.A., España.

Hutschenreuter A. (2008), Las compuertas geopoliticas del siglo XX, Centro Argentino de Estudios Internacionales (CAEI), Working paper 4, Programa Geopolítica, http://docplayer. es/43997571-Caei-las-compuertas-geopoliticas-del-siglo-xx-por-alberto-hutschenreuterworking-paper-04-programa-geopolitica.html [Consultado el 20.05.2018]

Isola, Emilio R. y Berra, Angel C. (1950), Introducción a la Geopolítica Argentina. Las influencias geopolíticas en la formación de nuestro Estado, Círculo Militar, Biblioteca del Oficial, vol. 390, Buenos Aires, Argentina.

Karns M. P., Mingst K. A. (2010), International Organizations. The Politics and Processes of Global Governance, Lynne Rienner Publishers, Boulder, London.

Kirshner J. (2010), Realist political economy: traditional themes and contemporary challenges, en: Routledge Handbook of International Political Economy (IPE) . IPE as a global conversation, M. Blyth (ed.), Routledge, USA y Canada.

Koslowski R., Kratochwil F. V. (1994), Understanding Change in International Politics: The Soviet Empire's Demise and the International System, "International Organization", vol. 48, no 2, pp. 215-247, The MIT Press, http://www.jstor.org/stable/2706931 [Consultado el 09.01.2012]

La Nación (29 de octubre de 2005), Una contracumbre para oponerse al ALCA, https:// www.lanacion.com.ar/751811-una-contracumbre-para-oponerse-al-alca [Consultado el 10.12.2017].

La Nación (8 de diciembre de 2004), Se creó la Comunidad Sudamericana, https://www. lanacion.com.ar/661119-se-creo-la-comunidad-sudamericana [Consultado el 10.12.2017].

Marichal Salinas C. (2010), Nueva historia de las grandes crisis financieras. Una perspectiva global, 1873-2008, Debate, Buenos Aires.

Marini J. F., Bandini R. (1980), Desarrollo y seguridad de la Argentina en el marco geopolítico Internacional, Hachette, Buenos Aires.

Milia J. G. (2015), Geopolítica de límites y fronteras de la Argentina, Dunken, Buenos Aires.

Ministerio de Seguridad de la Nación (15.02.2016), Gendarmería volverá a la frontera, http:// www.minseg.gob.ar/gendarmer\%C3\%ADa-volver\%C3\%A1-la-frontera [Consultado el 21/12/2017]

Ministerio de Seguridad de la Nación (25.07.2011), Comenzó el Operativo Escudo Norte, http://www.minseg.gob.ar/comenz\%C3\%B3-el-operativo-escudo-norte [Consultado el 21.12.2017]

Miranda R. (2012), Des-inserción argentina. Las políticas exteriores de Menem y Kirchner, "Revista Enfoques", vol. XI, no 17, 2012, pp. 85-103.

Ohmae K. (1997), El Fin del Estado-Nación. El Ascenso de las Economías Regionales, Editorial Andrés Bello, Santiago de Chile. 
Palacio P. (2016), Economía lícita informal: ¿Reminiscencia de prácticas antiguas o fenómeno que amenaza con imponerse en la realidad económica del nuevo milenio? Una mirada a los casos de la Triple Frontera y la economía argentina, en: Przeobrażenia geopolityczne $i$ nowe zagrożenia w Ameryce Łacińskiej - Transformaciones geopolíticas y nuevas amenazas en América Latina, K. Krzywicka, P. Trefler (coords.), Estudios Iberoamericanos de la UMCS, vol. IV, Lublin.

Palacio P., Papi L., Purciariello A. (2016), La triple frontera argentino-brasileño-paraguaya: economía no registrada, multiculturalidad y problemáticas ambientales comunes, en: Contrariedades socioeconómicas de América Latina en el siglo XXI, Editorial IMAGO MUNDI, Buenos Aires.

Palacio P. (2012), Industria y desarrollo en la Argentina de los albores del siglo XXI, en: Los desafíos de América Latina para el siglo XXI, M. de M. Llairó, E. Del Acebo Ibáñez (comps.), Editorial Claridad, Buenos Aires.

Scholte J. A. (1997), Global Capitalism and the State, "International Affairs" (Royal Institute of International Affairs 1944-), vol. 73, no 3, Globalization and International Relations (July 1997), pp. 427-452, Publicado por: Wiley on behalf of the Royal Institute of International Affairs Stable URL: http://www.jstor.org/stable/2624266. [Consultado el 27.05.2014].

Semanario Primera Plana (17 de febrero de 2016), Desde su creación el RTU facturó 1 millón de dólares por compras en Ciudad del Este, véase http://www.diarioprimeraplana.com/v1/ economia/item/3194-desde-su-creaci\%C3\%B3n-el-rtu-factur\%C3\%B3-1-mill\%C3\%B3nde-d\%C3\%B3lares-por-compras-en-ciudad-del-este [Consultado el 10/12/2017].

Semanario Primera Plana (17 de diciembre de 2014), Afirman que la ley del RTU debe ser reactivada con actualización de la lista, véase http://www.diarioprimeraplana. $\mathrm{com} / \mathrm{v} 1 /$ en-destaque/item/2003-afirman-que-la-ley-del-rtu-debe-ser-reactivada-conactualizaci\%C3\%B3n-de-lista [Consultado el 10/12/2017].

Sistema Económico Latinoamericano y del Caribe (SELA) (2014), Evolución del Mercado Común del Sur (MERCOSUR), Relaciones Intrarregionales, Secretaría Permanente del SELA, Caracas, Venezuela.

Snyder J. (1991), Myths of Empire. Domestic Politics and International Ambition, Cornell University, Ithaca and London.

Sputnik Mundo (22.07.2017), Operación Paraná: hito en la colaboración militar entre Brasil y Paraguay, https://mundo.sputniknews.com/defensa/201709221072584007-tropas-brasilparaguay-ejercito/ [Consultado el 21.12.2017].

Stiglitz J. E. (2003), Los felices 90. La semilla de la destrucción, Taurus, Madrid 2003.

Strange S. (2003), La retirada del Estado. La difusión del poder en la economía mundial, Icaria Editorial, 2a edición. Barcelona

Télam (17.05.2013), El 24 de marzo de 2004, el día que Kirchner hizo bajar el cuadro del Colegio Militar, http://www.telam.com.ar/notas/201305/17971-el-24-de-marzo-de-2004-el-dia-quekirchner-hizo-bajar-el-cuadro-del-colegio-militar.html [Consultado el 10.12.2017].

Trombetta E. (2017), Fuerza Aérea Argentina: "Lograr la Decepción". Operativo Fronteras - Escudo Norte, IEERI (Instituto de Estudios Estratégicos y Relaciones Internacionales), Círculo de Legisladores de la Nación, CABA 02.09.2017, https://www.zona-militar. com/2017/09/18/fuerza-aerea-argentina-lograr-la-decepcion-operativo-fronteras-escudonorte/ [Consultado el 10.12.2017].

WikiLeaks (2008), Paraguay: 2008 Country Report on Terrorism, http://wikileaks.org/ plusd/cables/08ASUNCION868_a.html [Consultado el 21.12.2017].
La geopolítica argentina relegada por condicionantes domésticos (2001-2017). Una mención al caso de la Triple Frontera

Priscila Palacio 